\title{
Construction and Application of Virtual Simulation Instrument Analysis System in Experimental Teaching
}

\author{
Wei Zhang, Huoying Xu, Baocheng Zhou, Yanrong Jia* \\ Department of Chemistry, School of Science \\ Zhejiang Sci-Tech University, Zhejiang Hangzhou 310018, China
}

\begin{abstract}
Based on the campus network, a virtual simulation instrument analysis experiment system was designed including a procedure of four steps: content selection, script writing, experiment edition, test and evaluation. And its structure was divided into three layers. The effects of the system application was changing the study mode and reforming the teaching mode. Furthermore, an open platform and the remote experiment also became reality, which could broaden the benefited range and radiating surface effectively. The benefits of the virtual experiment system were supposed to achieve in the aspects of arousing the students' enthusiasm of study, training student's skill and breaking through the difficulties in teaching.
\end{abstract}

Keywords—virtual simulation; instrument analysis; experimental system; experimental teaching

\section{INTRODUCTION}

Experiments are necessary for the advancement of scientific knowledge. However, experiments are equally important in Science subjects teaching and learning process because they allow the students to enter in direct contact with natural or real phenomena. Chemistry experiment is very significant for the chemical major students, which allow students to observe phenomena, test hypotheses, and apply their understanding of the real world. Sometimes the real experiments could be too dangerous or toxic to organize those experiments. Virtual Instrumentation (VI) could be used not only for the real-world instruments building, but also was useful for building applications, which simulate real-world devices and instruments operating, and for modeling the real chemical processes [1]. In these cases, the use of virtual experiments in the classroom might be a proper way for showing the experiment proper phenomena. In traditional instrument analysis experiment teaching procedure, the univocal teaching content and forms, the shortage of equipment and other constraint conditions would not meet the demand of training students' practical ability and innovative ability. With the developing of network and multimedia techniques, a new form of education called virtual simulation experiment education developed quickly [2]. Since 2013, many national virtual simulation experiment teaching center was funded by the ministry of education. Consequently, new teaching and learning methods based on using modern technology destined to emphasize the practical applications of theoretical concepts were developed. Using of virtual instruments is one of new way which can be used for designing different simulations of the real processes and illustrates the complex processes which are taking place in the real systems.

Some virtual experiments has been used in teaching and learning process, but they was absent of the open and remote application [1, 2]. Until now, Virtual simulation experiments have not yet in our chemical experiment teaching center, which severed nearly 400 students. The center has "basic type, synthesis, improve the innovative" three degrades experimental teaching system. In general, the lab practice is not only to cultivate the students' practical ability and 
experimental operation skills, but also remarkably cultivate students' innovation spirit and innovation ability. As for instrument analysis experiment, the instrument operation and qualitative or quantitative analysis process coexisted and crossed three degrades experimental teaching system. In addition, the instruments resource is limited in opening and sharing. Uneven students' knowledge level still required the virtual simulation experimental practice training and explored a new effective platform of remote teaching. The virtual instrument experiment was proved to be very efficient in Sciences teaching [1, 3]. Thus, it is eager to construct and apply the virtual simulation instrument analysis experiment teaching process.

The emergency of internet-based virtual technology promotes the development of experiment teaching, which can provides a vivid practicing environment in which every student will be a participant and act a role, so it could play a positive role in arousing the students' enthusiasm of study, training student's skill and breaking through the difficulties in teaching. In this paper, the construction plan and application of virtual simulation instrument analysis experiment system were proposed. In the next step, we would design our own virtual experiments using suitable existent software.

\section{CONSTRUCTION AND APPLICATION OF THE VIRTUAL SIMULATION EXPEIMENT SYSTEM}

\subsection{Design proposal}

Virtual simulation experiment system using a computer technology created a visual experimental operating environment. It would provide the simple and general interface, the accurately calculated and simulated experiment condition, the equipment operating status, the operation process of user [4]. Due to the characteristics of virtual property, practicality and openness, the experiment system was generally designed with the principle of generality, interactivity, sharing and security [5]. In fact, the system was developed predominantly according to the actual instrument analysis chemistry experiment schedule. Generally, the designing detail procedure was divided into four steps, as shown in Fig. 1 [6].

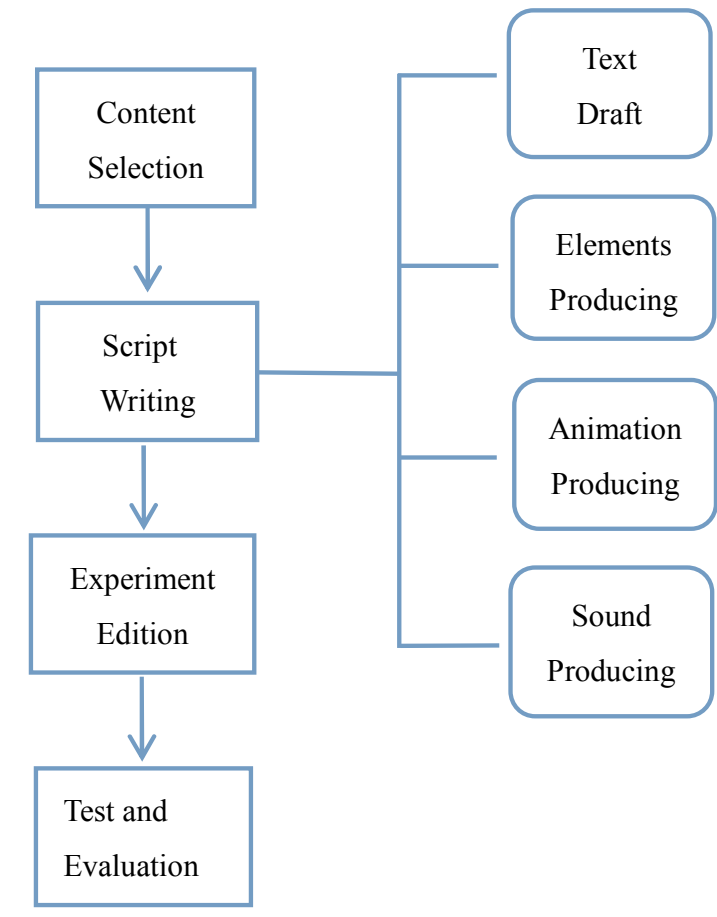

Fig.1 Design procedure of virtual simulation experiment

$$
\text { system }
$$

Firstly, each functional parts of instruments in the real world could be modeled by abstracting and simulation using physical or mathematical method. It is an integrative technical field which utilizes the computers and various chemically responsive tools to create model systems for conducting experiments in an actual or imaginary system [7]. Indeed, a mathematical model embodied a thought experiment, a causal hypothesis, and its falsifiable predictions. Virtual simulations performed using computers could be applied to any natural sciences or humanities subjects for conducting systematic analysis, linear and non-linear planning, prediction, decision making and management, as well as laboratory training [8] and became more significant in science experiments. The most important pedagogical function for virtual simulations would be the creation of a virtual lab course, which specifically refer to a computer simulation of experimental environments and processes that could be used by instructors or students to "conduct" experiments using a computer interface. Users would be able to acquire relevant knowledge and skills as well as conduct experiments that might be hard to accomplish with actual lab equipment.

Script writing is central to the system design and 
construction. It mainly includes the following aspects of text writing, instrument elements producing, animation producing, sound producing, etc. Because the purpose of simulation chemistry experiment teaching is to make up for the inadequacy of classroom teaching or realize the dangerous or poisonous chemical experiment in computer aided way, the experiment content choice requirement became the important and complicated step. Based on analyzing and understanding the experiment content, steps and skills, the animation and sound content was arranged carefully by using the interaction function, which produced in the design process using ActionScript language.

Thirdly, the experiment edition process was constructed using language of Adobe Flash and ActionScript respectively. In the construction process, it had to take into account the interface aesthetics, the interest and verisimilitude of the experiment process. Considered thoroughly, such as the functions of the equipment components, the basic principle, the experiment procedure, etc, a complete simulation system was integrated according to the simulation need of chemical experiment. Finally, the completed system was tested and evaluation by users to find out and amend the problems. Then the scientific and practical virtual simulation instrument analysis experiment system was obtained.

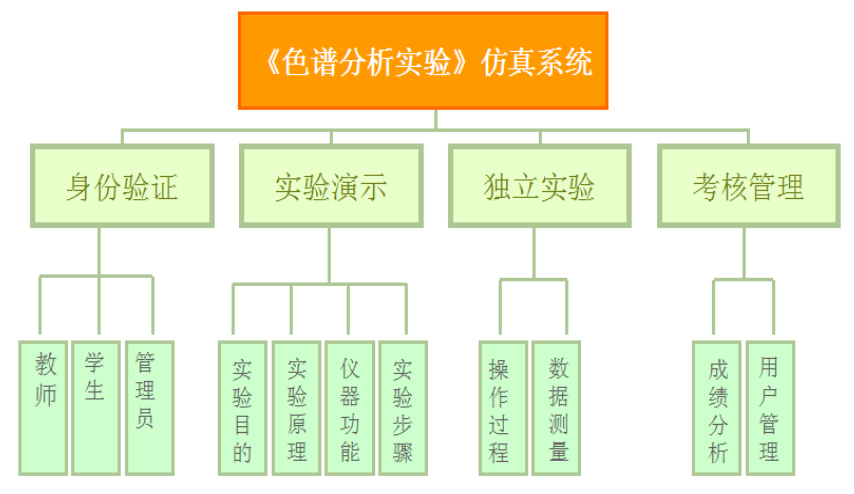

Fig.2 System structure of virtual simulation experiment modeling

As shown in Fig.2, the system structures is divided into three layers: the first layer implemented by Human-Computer interaction, the processing layer composed of four modules: user login, experiment process demonstrating, implement virtual operation, assessment and management [9]. The implement virtual operation module fetches the detailed experiment operation log from data management module, and then have simulation module re-simulate and represent the experiment process visually on screen. Experiment assessment and management module analyzed operation log and gave preliminary information, such as effective operation sets, experiment time distribution etc. Learners and evaluators completed experiments and evaluations through system interface respectively. In virtual experiment, interface converted learners' operations to internal commands and data, and transmitted them to the simulation module. On the other hand, the results of the operation that come from simulation module were transmitted to learners immediately, so the platform achieved the function of immediate response to the operation. In evaluation, the interface called modules in data process layer to analyze and reproduce the experiment process, and resulted to provide evaluator the helpful information. It's emphasized that the evaluators in the platform include both teachers and students. Communication among the students was an important and effective learning approach. So the virtual experiment encouraged students to participate in evaluation activities. Then it could be used not only for the real-world instruments building, but also could be useful for building applications.

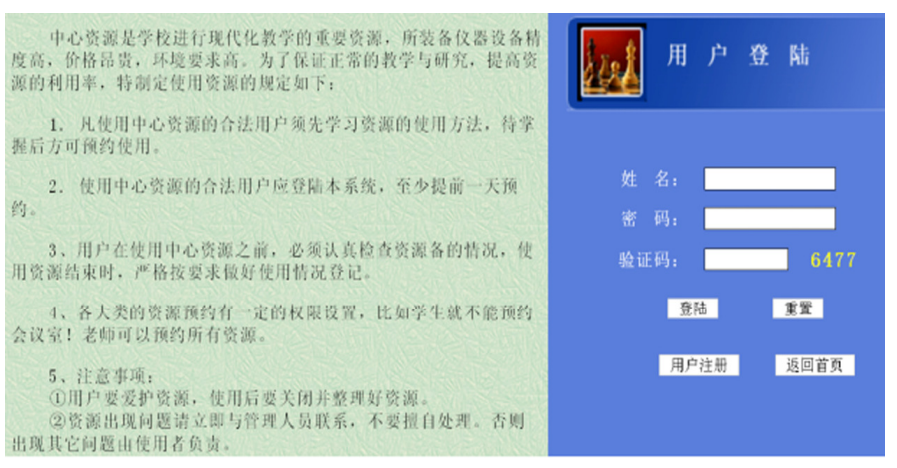

Fig.3 User login interface 


\section{中心实验}


Fig.4 Experimental system interface

The design of a simulation system security login interface, $\log$ on password security authentication, as shown in Fig. 3 (finished) and Fig. 4 (building). For virtual experiments system, the key benefit of ontological annotation was that defined interfaces. The scientific virtual experiment system will constructed and realized in the immediate future.

\subsection{Application effects in experiment teaching procedure}

Using virtual simulation experiments system, different virtual experiments or simulations of real processes can be designed. These virtual experiments can be used in the educational contexts for simulating the real phenomena which are taking place in different systems. In addition, the virtual experiments or simulations can be used by the teachers and students in the classroom in order to assure a logical learning process, based on practical aspects. The students only used a mouse or keyboard to operate the instruments system and freely chose experiment content and experiment process and observed all kinds of failure phenomenon absent of normal traditional operation, which greatly arouse the enthusiasm of the students' learning. Moreover, they played a real role in virtual learning environment, such as setting and changing the parameters. Virtual Experiments offered an innovative sense on teaching and learning, especially in cases where such laboratories were still not skilled. Compared with the traditional instrument analysis experiment teaching, the importance and benefit of using the virtual instruments in the teaching process was emphasized by the following aspects: changing the study mode, improving the teaching mode reform and fabricating the open experimental platform. All the changes could efficiently raise the teaching efficiency and the student's learning interest. It was also noted that the open character would broaden the benefit range effectively.

\subsubsection{Changes of study mode}

In traditional instrument analysis experiment, every students has a little chance to training skills due to the limited time and relatively scarce instruments. Firstly, the virtual experiment system broke the time constraints, which made student gain the training regardless of any time. Secondly, Pre-tests and post-tests was carried out by the students before and after the course respectively. Pre-test made the teacher only interpret the key and difficult points instead of all the content and reduce the students' blind operation, which saved many times to practice operation. In addition, it aimed students to have better understanding the teaching content, the experiment principle and experiment process. If students were not satisfied with experimental process or result of the experiment, they could do it after class without the wastage of the equipment and chemical reagents.

On the other hand, the students acknowledged some "Black Box" of the integrated instruments. In the experiments process, the students not only knew the individual parts of functions and characteristics, but simulated the whole process of operation instrument better. Moreover, according to the students' requirement, it allowed students to change the system parameters, to design the experiment scheme and to output test results in all forms.

\subsubsection{Reform of teaching mode}

Virtual instrument technology makes the discrete, independent process of data acquisition, data processing, data output and transport fuse together and affect each other to form a new technical method and specification. The instrument interface of human-computer interaction always met the new experiment teaching demand. This required the teacher's professional level to update timely [10]. Firstly, the teacher had to possess the innovation spirit and ability. They not only master the basic experimental theory knowledge, but need to more understand of the fusion and differences of virtual instrument analysis experiment and practical operation. Secondly, they also have to constantly update knowledge, 
such as the professional theoretical knowledge and background, the relevant multimedia technology and network information modernization.

\subsubsection{Open experimental platform building}

Compared with the virtual experiment used in teaching process, the virtual experiment system would much prefer to build an open experimental platform. Then the virtual simulation experiment system could be used without the restrictions of time and place. And it provided an interaction and communication platform for the students form the same or different majors [11]. In the experiment, the student had the dominant status and developed positivity and initiative. Moreover, they also select the experiment topic and content, organize experiment, repeated practice. If they were not satisfied with the experiment results or procedure, they could practice respectively to obtain the skillful handling ability. In addition, the virtual simulation experiment teaching system provides a new platform for teachers and students to exchange the ideas and communication. Especially for the cooperative company, the experiment system display the special advantage, such as providing and sharing the remote experiment resources to improve the level of operation or practice skill. Compared with acquisition of assets, it is easier to build, and it is facilitate to measure and control at long-distance. The application of the virtual instrument technology could save a lot of cost for purchasing equipment, laboratory construction and management, and improve the efficiency of experiments. Moreover, it could bring the reform of teaching method to keep up with international advanced experimental teaching level. In the near further, the system could promote the sustainable developing chemical experiment teaching and servicing platform.

Above all, the application of the virtual simulation of chemical experiment system is to build a virtual practice teaching system, deeply reveal the teaching content, provide a safe, economic conditions for the offline training students, make the practice training timely keep up with the pace of technological development. The main goals of the lesson become to guide the execution of the experiment, to give on-line instructions and information about the involved subjects, to stimulate the participation of the pupils, development of the exploration/investigation and experimenting capacity, through the use of set of virtual instruments. Learning by simulation is generally faster than in the traditional instruction in simulations can be more effective for performance improvement. The reasons for this effectiveness are justified by the conceptual change obtained by demanding students to state explicitly their suppositions and implicit reasoning. The created experiment was successfully in terms of clearly presentation of the lesson objectives and, at the same time, having the following advantages: easy access of each student to experiment, helping for the identification of cause-effect relationships through observation and interaction, underlying scientific models that are not easily percept from direct observation [1]. But it does not mean that traditional experimental methods would be discard. In fact, it was emphasized the importance of traditional experiment in the documents released by the Ministry of Education. It was clearly pointed out that the supplementary part of the virtual system to the real dominant experiment.

\section{CONCLUSION}

Virtual simulation instrument analysis experiment system based on campus network platform is one of the leading developmental ways in modern education. The experiment system edition process was constructed using language of Adobe Flash and ActionScript. In general, the detail design procedure had four steps: content selection, script writing, experiment edition, test and evaluation. The designed experiment system with three layers was constructed by introducing the computer virtual simulation technology in practice educational process. Compared with the traditional chemical experiment instrument analysis, it had the function of simulating the real situation. It could change the studying and teaching methods, improve the teaching efficiency, build an open experiment teaching platform. Besides, it could mobilize students' learning initiative and enthusiasm and improve college students' scientific research innovation ability. Moreover, the cooperate application of the real practice and the virtual experiment system not only reduce the expenditure of the instruments and equipment, but also expand the application scope. And it inspired the students' innovation consciousness, 
cultivate the students' scientific research innovation ability and improve the college students' ability of solving practical problems.

\section{ACKNOWLEDGMENTS}

We were sincerely grateful to the financial support from the projects of "Zhejiang Sci-Tech University teaching reform project-Study the Application of Virtual simulation technology in the instrumental analysis class experimental teaching", "Series Curriculum Construction on the Polymer Materials (or marine materials) for Material Chemistry Major Undergraduates" and "Higher Education Teaching Reform Project in Zhejiang Province- Application of Virtual Simulation Technology in Comprehensive Reform of Chemistry Experiment Course".

\section{REFERENCES}

[1] C. Dumitrescu, R.L. Olteanu, L.M. Gorghiu, G. Gorghiu, G. State, "Using virtual experiments in the teaching process," Procedia Social Behav. Sci., Vol. 1, pp. 776-779, January, 2009.

[2] L. Lei, J. Liu, X. Yang, "Research of the remote experiment system based on virtual reality," Phys. Procedia, Vol. 24, pp. 1199-1206, April, 2012.

[3] L.M. Gorghiua, G. Gorghiub, C. Dumitrescua, R.L. Olteanua, M. Bîzoib, A.M. Suduc, "Implementing virtual experiments in Sciences education challenges and experiences achieved in the frame of VccSSe Comenius 2.1. Project, "Procedia Social. Behav. Sci., Vol. 2, pp. 2952-2956, January, 2010.

[4] B. Zhang, "Application and development prospect in computer simulation experiment teaching," J. Tech. College Education, Vol. 24, pp. 116-118, March, 2005.

[5] X.M. Guan, T.M. Dai, T.B. Wang, "The design of the virtual Experiment platform of colleges and research of teaching appilcation," Natural Sci. J. Harbin Normal University, Vol. 31, pp. 88-90, June, 2015.

[6] C. Zhang, "Design and development of simulation experimental system," Coal Tech., Vol. 32, pp. 208-210, November, 2013.

[7] D.B. Clark, C.M. D'Angelo, M. Menekse, "Initial structuring of online discussions to improve learning and argumentation: Incorporating students' own explanations as seed comments versus an ugmented-preset approach to seeding discussions," J. Sci.Edu. Tech., Vol.18, PP. 321-333, April, 2009.

[8] M. Jou, Y.T. Lin, D.W. Wu, "Effect of a blended learning environment on student critical thinking and knowledge transformation. Interactive Learning Environments," 961485. http: //dx.doi.org /10.1080 /10494820. 2014.

[9] R. Yao, "Design of inquiry virtual experiment platform," Energy Procedia, Vol. 16, PP. 1579-1585, December, 2012.

[10] Y. Bai, J. Zhang, J. Pan, Y.Q. Li, "Application of "virtual labaratory" in instrumental analysis teaching in colleges and universities," Experimental Technology and Management, Vol. 18, PP. 169-172, November, 2011
[11] X.Y. Zhou, K.C. Fan, H. Liu, "Discussion on VM aided computer experiment teaching," J. Kunming Univers. Sci. Tech. (Science and Technology), Vol. 33, PP. 34-37, June, 2008. 